\title{
Generational accounts for Belgium: fiscal sustainability at a glance
}

\author{
André Decoster • Xavier Flawinne • \\ Pieter Vanleenhove
}

(C) Springer Science+Business Media New York 2013

\begin{abstract}
This paper uses generational accounts to analyse the long term sustainability of Belgian public finances. We derive age-profiles of detailed tax and expenditure categories from micro data and microsimulation models, and plug them into a long run demographic projection. We assess fiscal long term sustainability under current fiscal and budgetary policy for the base year 2010, and perform simulations of counterfactuals to determine the relative contribution of the most important factors of the long run unsustainability. This update of the generational accounts for Belgium shows that, not unexpectedly, the budgetary situation in Belgium violates the intertemporal budget constraint and hence is unsustainable in the long run. The current level of explicit debt, however, only plays a minor role in explaining this sustainability problem. Ageing and the related increase in age related expenditures are the main drivers of the long run fiscal imbalance and the high level of implicit debt. We disentangle the Belgian generational accounts into their regional components and show that the major explanation for regional differences in generational accounts is not divergent demographic projections, but the wide differences in socio-economic situations, as revealed by the region specific ageprofiles.
\end{abstract}

Electronic supplementary material The online version of this article (doi:10.1007/s10663-013-9223-1) contains supplementary material, which is available to authorized users.

A. Decoster · P. Vanleenhove $(\bowtie)$

Department of Economics, KULeuven, Naamsestraat 69, 3000 Leuven, Belgium

e-mail: pieter.vanleenhove@kuleuven.be

A. Decoster

e-mail: andre.decoster@kuleuven.be

X. Flawinne

CREPP-HEC Université de Liège, Bat. B31 Economie publique appliquée, Boulevard du Rectorat 7 ,

4000 Liège, Belgium

e-mail: xflawinne@ulg.ac.be 
Keywords Generational accounting - Fiscal imbalance - Sustainability - Ageing · Demographic change

JEL Classifictions $\mathrm{H} 50 \cdot \mathrm{H} 60 \cdot \mathrm{J} 10$

\section{Introduction}

Since the financial crisis turned into a sovereign debt crisis, the public at large in European countries has been battered with alarming quotes about widening deficits, rising debt to GDP ratio's, unsustainability of public finances, and ever more harsh austerity plans. Belgium is not an exception to this general picture. As in many other countries, the (partial) transformation of the private debt overhang into sovereign debt, caused a U-turn in the time-path of the budgetary situation of Belgium. The fiscal deficit and debt level forecasts for 2012 are respectively -3.1 and $100.5 \%$ (AMECO 2012). Also the long overdue agreement on the budget 2012 (finalized in December 2011) was framed within immediate revisions (March 2012) due to disappointing realisations. It certainly would be an understatement that these fiscal imbalances would not get enough attention.

Precisely these urgent worries about cyclical and short term problems in the fiscal stance of countries, threaten to conceal the long term picture of structural and long term fiscal imbalances. The more "because the factors contributing to short-term debt accumulation differ substantially from those that will affect debt accumulation over the longer term" (Auerbach 2011 p. 1). This is where the analysis of this paper comes to the fore. It does not fit in a short term framework, but analyses the long term sustainability of the Belgian public finances by applying the method of generational accounting on the data of 2010.

Generational accounting has been introduced by Auerbach et al. (1991) as an alternative way of looking at the fiscal stance of countries. They launched the methodology as a response to the shortcomings of deficit accounting. The main criticism against the use of the current deficit as a measure of fiscal sustainability of government finances is that it focuses exclusively on the annual flows of expenditures and receipts. The obvious example is a change in legislation which increases (or decreases) future pension entitlements. This policy choice will not show up in the current deficit, but might seriously affect long run fiscal prospects. Generational accounts are precisely designed to take into account the effects of policies on current and future generations. They report, in present value, the amount of net taxes a representative member of each generation will have to pay during his or her remaining lifetime, given fiscal and social policy of the base year.

Actually, two different types of generational accounts can be constructed: "rest of life" generational accounts, which evaluate the remaining net taxes a representative member of each cohort will have to pay for the rest of his or her life, and "life cycle" generational accounts, which not only take the remaining net 
taxes into account, but also net taxes paid in the past. In this paper we only develop and calculate "rest of life" generational accounts.

The first international comparison of generational accounts and their accompanying sustainability indicators are Auerbach et al. (1999) and Raffelhüschen (1999a, b). Both studies provide a detailed description of the generational accounting methodology and illustrate this on multiple countries. As far as Belgium is concerned, Auerbach et al. (1999) and Raffelhüschen (1999a, b) conclude that the unsustainability of public finances is not considerably different from the one found in other countries. In the last decades, several other generational accounting studies have been published for many countries. Hagist (2008) provides an overview of the most recent studies of 28 different countries using generational accounts to assess the fiscal situation. However, despite this presence of multiple studies for individual countries, there is a lack of recent studies that actually compare generational accounts at an international level, like Auerbach et al. (1999) and Raffelhüschen (1999a, b). The most recent study that compares generational accounts and the fiscal outlook in several countries is Hagist et al. (2009a, b). ${ }^{1}$

Generational accounts are not uncontroversial. Haveman (1994) summarizes the most important criticisms and limitations. Firstly, generational accounts are calculated under the assumption of the persistence of current policy. But governments will definitely change taxation, spending and borrowing policy in response to changes in the economic, social and political environment. Haveman (1994) argues that this is not the government which appears on the scene of generational accounting. A second criticism concerns the sensitivity of the estimates to the discount and growth rates used in the intertemporal calculations. To overcome this, to a certain extent arbitrary, choice, most generational accounting studies conduct sensitivity analyses. Anyhow, Auerbach et al. (1994) admit that the use of a constant discount rate is an oversimplification and that the methodology can be improved in this respect. A third comment concerns the lack of behavioural change. The method of generational accounting does not allow for consumption or labour supply responses to taxes and transfers reflected in the accounts, let alone more general macro-economic interactions between sectors and/or general equilibrium effects. As such, the calculation of generational accounts is a purely arithmetic exercise and fully respects its designation as generational 'accounting'. In addition to that, standard generational accounting studies do not make any normative statements in which the welfare of current and future generations is traded-off in an elaborate and explicit ethical framework of intergenerational justice.

It is not surprising therefore that generational accounting has never succeeded in replacing the current budget deficit as the main focus of sound fiscal policies. Yet, even Haveman concludes his critical review in a nuanced way: 'The idea of tracking the monetary effect of fiscal policy measures on representative members of all present and future age groups is enormously attractive. Indeed, what legislator or economist—indeed, what citizen—would not desire such information? In principle,

\footnotetext{
1 They analyse the long term fiscal sustainability of Spain, Switzerland, Austria, Norway, Germany, France, United Kingdom and the United States.
} 
a version of generational accounts could be a valuable public finance tool' (Haveman 1994, p. 106).

This also summarizes our own motivation to update the Belgian generational accounts. The most recent ones date back to more than a decade ago: Stijns (1999) and Dellis and Lüth (1999) with 1995 as base year, and Liégeois (2001) who derives generational accounts for Belgium in the context of a computable general equilibrium model. ${ }^{2}$ In the course of the update, we have improved the quality of the calculations of the Belgian generational accounts by introducing some new elements. The first, and most important one, is the use of microdata and microsimulation models to derive age profiles for the most important taxes and benefits. We also use microsimulation models to simulate the effect of higher employment rates on the generational accounts. Secondly, we disentangle the Belgian generational accounts into regional accounts for Flanders, Wallonia and Brussels. Finally, we investigate the main determinants of the long term unsustainability of Belgian public finances, by simulating counterfactuals such as the removal of initial debt, of ageing, or of rising health-care expenditures.

These updated generational accounts and the sustainability indicators derived from them, will allow us to compare our results with other recent studies which gauge the sustainability of Belgian public finances. Saintrain (2010) calculates, among other things, a sustainability indicator which reflects the permanent and immediate increase in the primary balance in order to reach sustainable public finances in the long run. His indicator is similar to the S2-indicator, frequently used by the European Commission in their yearly sustainability reports (European Commission 2010). Both studies conclude that public finances are not sustainable in the long run and primary balances have to adjust by respectively 6.2 and 6.5 percentage points of GDP. Both studies do not rely on micro statistics but use a macro model to estimate future receipts and expenditures of the government. This makes the comparison of the degree of unsustainability obtained in this macro framework, with the results from our generational accounting framework all the more interesting. Also Auerbach (2011) and Raffelhüschen and Moog (2011) look at the Belgian fiscal situation. They use the OECD- methodology to assess fiscal sustainability, a method which also differs in some ways from the generational accounting method. ${ }^{3}$ They obtain results in line with Saintrain (2010) and the European Commission (2010). Needless to say that we consider our paper not as a substitute for these recent assessments, but as a valuable complement based on a different methodological framework and essentially using microdata.

The rest of the paper is structured as follows. Section 2 starts with a brief discussion of the generational accounting methodology and some sustainability indicators. Section 3 reports the data requirements and sources which have been

\footnotetext{
${ }^{2}$ Cattoir and Docquier (2004) also calculate generational accounts for Belgium for the year 1999. However, they use the methodology for a very different purpose since they try to find a new debt-sharing rule between seceding regions and do not consider the issue of sustainability of public finances.

3 There are two main differences. First, the projection of non-age related expenditures differs substantially from the generational accounting method and secondly, the OECD method works with a finite time horizon. For a detailed comparison of the OECD method and the Generational accounting methodology, see Benz and Fetzer (2006).
} 
used and Sect. 4 presents the generational accounts and sustainability indicators at the Belgian level for base year 2010. We also determine the important factors of unsustainability by means of the simulation of counterfactuals, such as a higher employment rate of elderly workers in Belgium. In Sect. 5 we briefly discuss the decomposition of the regionalized generational accounts and look more in detail at the different effects of demographic changes in the three regions. The last section concludes.

\section{Generational accounting and sustainability}

In this section we briefly present the methodology of generational accounting and the sustainability indicators we derive from it. For a more detailed discussion, we refer the reader to Decoster et al. (2011).

Denoting the level of debt at the end of period $t$ by $B_{t}$, the primary balance of period $t$ by $P B_{t}$, and the discount rate, assumed to be constant, by $r$, the intertemporal budget constraint of the government, from which sustainability indicators will be derived, can be written as:

$$
B_{t}=\sum_{s=t+1}^{\infty} \frac{P B_{s}}{(1+r)^{s-t}} .
$$

It states that the current level of debt (in period $t$ ) has to be covered by all future primary surpluses (or deficits). Indicators of the unsustainability of public finances gauge the extent in which (1) is violated.

The link with a generational accounting framework is obtained by decomposing the primary balance of each period, $P B_{s}$, into contributions of different cohorts living in that period, and then re-aggregating this decomposition according to cohort. With $k$ referring to the birth year of a cohort, we denote the primary balance of all members of cohort or generation $k$ at time $s$ by $P B_{s, k}$. This cohort-specific primary balance consists of the contribution of generation $k$ to government revenues in the form of payments of income, corporate and indirect taxes and social security contributions on the one hand, and the benefits this generation $k$ enjoys in the form of government expenditures such as public goods, family allowances, health care expenditures, replacement incomes (unemployment benefits, pensions, ...) etc. Adding-up all these contributions and benefits over the remaining lifetime of all members of generation $k$ and expressing it in present value at time $t$, leads to:

$$
N_{t, k}=\sum_{s=t+1}^{\infty} \frac{P B_{s, k}}{(1+r)^{s-t}} .
$$

We call $N_{t, k}$ the net tax payments of cohort $k$.

A generational accounting exercise makes projections of these primary balances, $P B_{s, k}$ 's, in each future period for each cohort. The assumptions, on which these projections are based, are expressed in terms of per capita tax payments and per 
capita expenditures in each period. We therefore write the total primary balance $P B_{s, k}$ as:

$$
P B_{s, k}=\tau_{s, k} \cdot P_{s, k},
$$

where $\tau_{s, k}$ refers to the per capita net payment in period $s$ of a representative individual from cohort $k$ living in period $s$, and $P_{s, k}$ denotes the number of people of cohort $k$ still alive at time $s$. The latter factor, $P_{s, k}$, is the demographic input of the model and is obtained from demographic projections.

The projection of the first factor on the RHS of (3), the net per capita tax payment $\tau_{s, k}$ for future generations, is based on the assumption that the per capita tax payment of a currently living age-cohort is informative of the per capita net tax payment of a future cohort when this future cohort will have reached the same age. The cohort born in period $k$ has age $a=s-k$ in period $s$. The assumption underlying the projection can then be expressed as:

$$
\begin{aligned}
\tau_{s, k} & =\tau_{t, t-(s-k)} \cdot(1+x)^{s-t} \\
& =\tau_{t, t-a} \cdot(1+x)^{s-t}
\end{aligned}
$$

where the second factor is introduced to have the net tax payments growing with the real rate of productivity growth $x .{ }^{4}$ Expression (4) highlights the crucial assumption underlying generational accounting applications: all information on future next tax payments $\left(\tau_{s, k}\right)$ is derived from net tax payments in base period $t$ for different age groups living in this base period. These $\tau_{t, t-a}$ 's are the so-called age-profiles of taxes and expenditures.

In practice net tax $\tau_{s, k}$ is disaggregated into $n$ different revenue and expenditure categories such as personal income taxes, social security contributions, indirect taxes, capital taxes, corporate taxes, unemployment benefits, pensions, child benefits, health-care, general public goods, etc. Denoting each element with the subscript $i$ we have:

$$
\tau_{s, k}=\sum_{i=1}^{n} \tau_{s, k, i},
$$

with an age profile for each specific $\tau_{s, k, i} \cdot{ }^{5} \mathrm{We}$ retrieve these age profiles of different tax and benefit components from microdata to microsimulation models, as described in Sect. 3.

A generational account, $G A_{t, k}$, is defined as the average net payment during the remaining lifetime of an individual of cohort $k$. The average is obtained by dividing the net tax payments of cohort $k$ over the whole time span $t$ up to $T$ by the number of individuals of that cohort $k\left(P_{t, k}\right)$ :

\footnotetext{
${ }^{4}$ Productivity gains affect both the absolute level of future age-specific tax payments and transfer receipts. However, the purpose of generational accounting is not to forecast these productivity effects. The literature assumes that both age-specific taxes and transfers grow with a constant and time invariant productivity growth rate $\mathrm{x}$.

${ }^{5}$ Note that each specific age profile grows over time according to the constant productivity growth rate $\mathrm{x}$.
} 


$$
G A_{t, k}=\frac{N_{t, k}}{P_{t, k}}
$$

The generational account of a newborn in period $t, G A_{t, t}$, will be of special importance because it will be used to calculate the generational imbalance.

This brings us to the sustainability indicators. Since generational accounting is a decomposition of the primary balance $P B_{t}$ in the RHS of (1), it is easily seen that (1) can be rewritten as:

$$
\begin{aligned}
B_{t} & =\underbrace{\sum_{k \leq t} N_{t, k}}_{\text {current generations }}+\underbrace{\sum_{k>t} N_{t, k}}_{\text {future generations }} \\
& =\quad C U_{t}+F U_{t},
\end{aligned}
$$

where $C U_{t}$ denotes the sum of the discounted future primary balances of the currently living generations, and $F U_{t}$ the corresponding concept for the future generations that are not yet born in year $t$.

A first way to express the unsustainability in the long run is by observing that the intertemporal budget constraint (7) can be written as:

$$
B_{t}-\left(C U_{t}+F U_{t}\right)=0 .
$$

The left hand side of Eq. (8) is denoted $I P L_{t}$ in the following and stands for the intertemporal public liabilities. They consist of explicit (gross) debt $\left(B_{t}\right)$, future assets (or liabilities) incurred by net tax payments of currently living generations $\left(C U_{t}\right)$, and future assets (or liabilities) incurred by net tax payments of future generations $\left(F U_{t}\right)$.

A sustainability gap will reveal itself as

$$
I P L_{t}=B_{t}-\left(C U_{t}+F U_{t}\right)>0 .
$$

We calculate the actual $I P L_{t}$ by using future liabilities incurred by net taxes of the future generations $F U_{t}$ under the assumption that current and future generations face the same fiscal policy. We report the value of these intertemporal public liabilities relative to the present value of all future GDP. ${ }^{6}$ Assuming that output per worker increases over time with the productivity growth $x$, we project future GDP by multiplying output per worker, which grows with the rate of productivity, with the projected workforce in the future, which we retrieve from the demographic projection.

An alternative way to express the violation of the intertemporal budget constraint, consists in expressing the adjustment needed in the discounted future primary balances of the future generations $\left(F U_{t}\right.$ in Eq. (7)) to restore the equality of Eq. (8). We denote this required adjustment as

\footnotetext{
${ }^{6}$ In some papers, e.g. Raffelhüschen $(1999 \mathrm{a}, \mathrm{b})$, these intertemporal public liabilities are presented relative to current GDP. However, we prefer to present liabilities relative to the present value of all future GDP's, as is done in e.g. studies of the Congressional Budget Office (CBO). This way of representing the sustainability problem allows us to compare sustainability gaps between different countries with other population evolutions. Different population projections influence the future ability of countries to face the sustainability problem. Working with the present value of all future GDP's takes this caveat into account.
} 


$$
F U_{t}^{*}=B_{t}-C U_{t}
$$

Indicator $F U_{t}^{*}$ expresses how the primary surpluses of all future generations have to be adjusted to comply with the intertemporal budget constraint, given the primary surpluses induced by the current fiscal policy for the currently living generations over the rest of their lifetime. This indicator is easily calculated, since one only needs information about the current debt level, and about the generational accounts of currently living generations.

Implicitly $F U_{t}^{*}$ also defines an adjustment in the generational accounts of the future generations, $G A_{t, k}^{*}$, with $k>t .{ }^{7}$ In practice one mostly assumes that net tax payments of all future generations are adjusted proportionately:

$$
\tau_{s, k}^{*}=\lambda . \tau_{s, k},
$$

with the factor $\lambda$ now measuring the degree of unsustainability.

In Sect. 4 we will not report this adjustment factor $\lambda$, but compare the GA of a newborn in base period $t\left(G A_{t, t}\right)$ with the fiscally sustainable GA of newborn in period $t+1\left(G A_{t, t+1}^{*}\right)$. The difference between $G A_{t, t}$ and $G A_{t, t+1}^{*}$, is called 'generational imbalance'. If this difference is positive, public finances are untenable in the long run: future generations will have to pay higher net taxes to satisfy the intertemporal budget constraint.

\section{Data requirements and availability}

The method of generational accounting requires population projections reflecting future demographic changes, a base year government budget preferably decomposed into different types of expenditures and revenues, age-profiles to allocate these net taxes across age groups (or cohorts), and assumptions about productivity growth and discount rates.

We use the official population projections for 2007-2060 of the Federal Planning Office and the National Institute of Statistics. In order to accommodate the infinite time horizon of the GA-methodology to the finite horizon in these projections, we first truncate the calculations after 200 years (in 2310) and add the remainder term, as described in Hagist et al. (2009a, b) to account for the infinite horizon. Hagist et al. (2009a, b) suggest applying the same parameters of the official population projections of the base year to extend these population forecasts. However, as we have no access to the demographic model underlying the official population projections, we were forced to adopt an alternative solution. Since we wanted to properly integrate the increased life expectancy of all generations living in base year 2010, and since we assumed a maximum age of 105 years, we first extrapolated the official demographic projections from 2060 up to 2115 . We did this by calculating the average yearly growth rate in population for different

\footnotetext{
7 See Decoster et al. (2011) for details on the link between $F U_{t}^{*}$ and the $G A_{t, k}^{*}$ 's.
} 


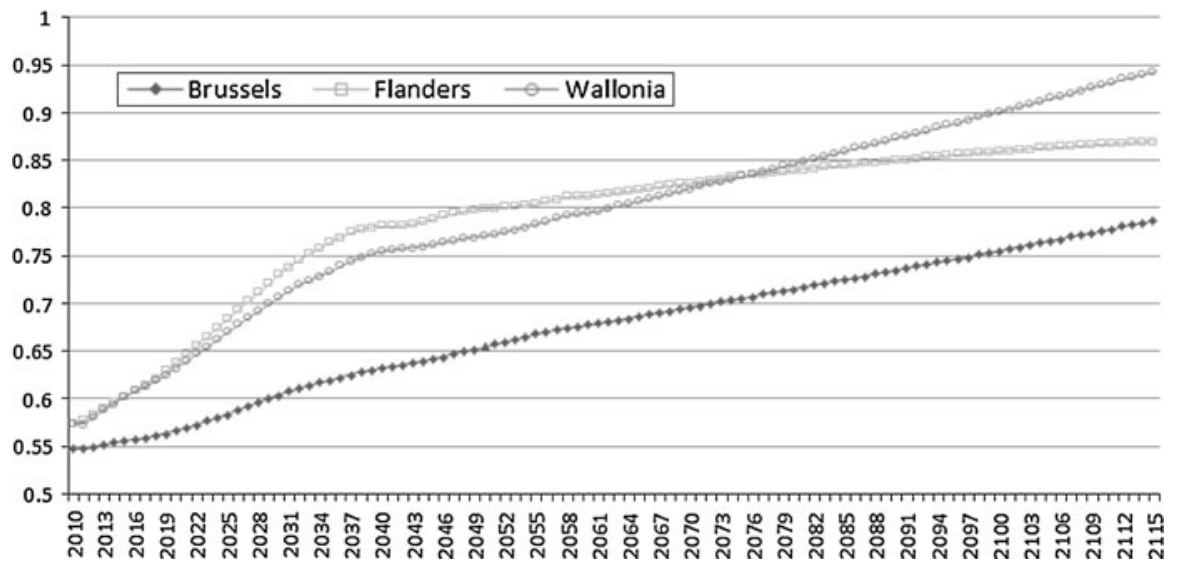

Fig. 1 Dependency ratio for the three Belgian regions. Source Federal Planning Office (2010) own calculations

subgroups between 2055 and $2060 .{ }^{8}$ These growth rates are then used to extend the population projections up to 2115 . As such, we assume that the evolution of the population between 2060 and 2115 follows a similar pattern as the evolution between 2055 and 2060. ${ }^{9}$ Second, we assume a constant population between 2115 and 2310 .

Figure 1 summarizes the population projections by means of one crucial statistic: the dependency ratio, defined as the ratio between the sum of age groups 0-16 and older than 65 in the numerator over the age groups 17-65 in the denominator. We display the region specific projections to show that ageing is not uniformly spread over the three Belgian regions. Both the level of the dependency ratio and its increase are higher in Flanders and Wallonia than in Brussels. In Sect. 5 we investigate the consequences of this differential demographic change across the regions within a regionalized generational accounting framework.

To clean the base year government budget from cyclical components, we started from the observation by the Belgian High Council of Finances (2011) that in base year 2010, the structural Belgian primary balance was break-even, and amounted to structural revenues and primary expenditures of $46.8 \%$ of GDP (or 165 billion $€$ ). ${ }^{10}$ On the revenue side, we adjusted all categories of actual revenues proportionately (keeping their share in total revenues constant), such that total revenues amounted to $46.8 \%$ of GDP. ${ }^{11}$ At the expenditure side, we only cleaned unemployment benefits, sickness and disability benefits, and early retirement benefits from their cyclical

\footnotetext{
${ }^{8}$ We calculated these growth rates for the following age-groups: $0-11,12-18,19-25,26-45,46-55$ year and $65+$.

9 As a sensitivity analysis, we have checked whether the results change significantly when using a different time interval than 2055-2060. The results remained relatively constant.

10 The non cyclically adjusted primary deficit was $1 \%$ of GDP in 2010.

11 This is a simplification, the cyclical component being obviously different for indirect taxes, corporate taxes, or social security contributions. Sensitivity analysis regarding this assumption showed that it had no significant impact on the results.
} 
Table 1 Belgian structural receipts and expenditures in 2010 (in million €)

\begin{tabular}{lrrlrr}
\hline Revenues & & \% GDP & Expenditures & \multicolumn{2}{c}{$\%$ GDP } \\
& & 2010 & & 2010 \\
\hline Capital taxation & 2,388 & 0.7 & Wages public sector & 32,696 & 9.3 \\
Income taxation & 42,927 & 12.2 & Birth allowances & 127 & 0.0 \\
Corporate taxation & 9,703 & 2.8 & Family allowances & 5,767 & 1.6 \\
Indirect taxation & 43,598 & 12.3 & Education & 15,804 & 4.5 \\
Social security contributions & 47,925 & 13.6 & Health-care & 24,514 & 7.0 \\
Non-fiscal non-parafiscal & 18,462 & 5.2 & Sickness and disability & 4,313 & 1.2 \\
$\quad$ & & & benefits & & \\
revenues & & & Unemployment benefits & 5,580 & 1.6 \\
& & & Pension benefits & 29,221 & 8.3 \\
& & & Other expenditures & 46,981 & 13.3 \\
Total & 165,003 & 46.8 & & 165,003 & 46.8 \\
\hline
\end{tabular}

Source National Bank of Belgium, Higher Council of Finances

component. Table 1 shows the result. We decomposed revenues into 6 different categories, and primary expenditures into 9 groups.

Revenues and expenditures from Table 1 need to be allocated across age groups. In contrast to many other studies which calculate generational accounts, we retrieve age-specific profiles for different taxes and expenditures as much as possible from microdata to microsimulation models.

For social security contributions, sickness and disability benefits, unemployment and pension benefits, we generated gender specific age-profiles by using the microsimulation model MIMOSIS. ${ }^{12}$ This model also generated age-profiles for personal income taxes. This age profile was not gender specific since the personal income tax liability is calculated at the household level. We therefore assumed the age-profile for personal income taxes to be the same for men and women. Ageprofiles for indirect taxes were generated by an indirect tax extension of the microsimulation model EUROMOD, based on the household budget survey of $2003 .^{13}$

We did not succeed in updating the age profiles for capital and corporate taxation, compared to the ones used in Dellis and Lüth (1999), and hence continued to use these profiles. The Vademecum of Financial and Statistical information about Social Security in Belgium of the Federal Public Service Social Security of 2011 gives a detailed overview of the gender specific distribution across age groups of health-care expenditures. The age-profiles for family allowances are retrieved from

\footnotetext{
12 MIMOSIS stands for Microsimulation Model for Belgian Social Insurance Systems, a microsimulation model developed at the University of Leuven (CES), University of Liège (CREPP) and the University of Antwerp (CSB) in partnership with, and funded by FPS Social Security and Federal Science Policy. The model is based on administrative data for more than 300,000 individuals and 100,000 households from 2001 and is now in use and maintained by FPS Social Security. For more information, see Decoster et al. (2007) or http://www.socialsecurity.fgov.be/.

13 See Decoster et al. (2009), Decoster et al. (2010), and Sutherland et al. (2009) for details of this extension of EUROMOD.
} 
the website of the Federal Service of Family Allowances. The age-profile for birth allowances is straightforward, since the amount can be imputed directly to the newborn. The age-profile for educational expenditures is based on data available from the Flemish and French communities. Finally, we did not try to allocate "Wages in the public sector", "Other expenditures" and "Non-fiscal and nonparafiscal revenues" to specific age groups. We distributed these categories uniformly across all age groups. The resulting age-specific averages for all expenditures and revenues of Table 1 and for base year 2010 are shown in the appendix.

In line with the literature, we make the assumption that age-profiles remain constant over time. This certainly is a simplification, since the effect of increased female participation in the labour market e.g., and the resulting higher pension entitlements, are not yet reflected in the 2010 age profiles of pension benefits. In future research this assumption could e.g. be relaxed by relying on dynamic microsimulation models.

In the baseline scenario we assume a discount rate of $3 \%$ and an annual productivity growth per capita of $1.5 \%$, the rate used by the Ageing Commission in its 2010 report. Growth is assumed to be constant over time and used to uprate all net taxes according to Eq. (11). We make one exception though. Known as the "Newhouse conjecture" - see Newhouse (1992) - health-care costs per capita grow faster than real growth, due to medical technological progress. To account for this, we calibrated the growth rate of health care expenditures on the one of the 2010 report of the Ageing Commission. ${ }^{14}$ This led to a growth rate of $2.2 \%$ per year, or 0.7 percentage points higher than the productivity growth of $1.5 \% .{ }^{15}$ We examine the robustness of our results with respect to the assumptions about discount factor and growth rate by conducting a sensitivity analysis.

\section{Generational accounts at the Belgian level}

This section presents the gender specific generational accounts for Belgium in base year 2010 in the first subsection. We then apply these GA's to investigate the long term sustainability of Belgian public finances. In the third subsection we quantify the relative contribution of explicit debt, of ageing and of employment on fiscal sustainability.

\subsection{Generational accounts for Belgium in 2010}

Table 2 displays the gender specific generational accounts for the currently living generations in Belgium in 2010. We first focus on the first row of the table: the GA

\footnotetext{
14 Using our population projections and assumed real growth, we calculated the average percentage point adjustment for health care expenditure, needed to reproduce the projected evolution of health care cost as a share of GDP by the Ageing Commission. For another study that includes an increased health care cost per capita growth rate, see Hagist et al. (2005).

15 To avoid health care costs exceeding the level of GDP, we also impose that from 2050 onwards, health care costs again grow in line with productivity growth.
} 
Table 2 Generational accounts for Belgium 2010 (in €)

\begin{tabular}{lcccc}
\hline Age & GA male & GA female & $\begin{array}{l}\text { GA representative } \\
\text { individual }\end{array}$ & $\begin{array}{c}\text { GA female with same } \\
\text { age profile as men }\end{array}$ \\
\hline 0 (newborn) & $-79,097$ & $-211,665$ & $-143,786$ & $-120,938$ \\
5 & $-25,810$ & $-169,400$ & $-95,751$ & $-73,116$ \\
15 & 125,673 & $-40,226$ & 45,018 & 75,270 \\
30 & 132,586 & $-21,463$ & 56,147 & 62,012 \\
45 & $-126,702$ & $-200,877$ & $-163,388$ & $-211,783$ \\
60 & $-331,666$ & $-318,749$ & $-325,175$ & $-428,727$ \\
75 & $-233,986$ & $-254,026$ & $-245,272$ & $-303,898$ \\
90 & $-120,162$ & $-137,586$ & $-132,876$ & $-131,605$ \\
\hline
\end{tabular}

for a newborn. In line with results for many other Western countries, the GA for newborns in the base year is negative: on average $€-143,786$.

The difference between both genders is striking, and again in line with findings in other studies (see for example Bonin 2000). For a male newborn the present value of what he gets from the government exceeds the present value of taxes and contributions he pays by $€ 79,097$. The female shortfall is almost three times that large: $€-211.665$.

To assess the relative importance of the expected demographic evolution and of the age-profiles of taxes and benefits in this gender difference, we simulated the female GA under the assumption that both genders had the same, male, age profile. This amounts to remove all differences between men and women (e.g. participation rates, average wages and hence contributions, etc.), except for longer female life expectancy in the baseline, and the divergent projected increase in life expectancy. The results are displayed in the fourth column of Table 2. The substantial reduction of the female GA of $-211,665$ to $-120,938$ reveals that the initial difference was mainly driven by the different age-profiles, which are primarily related to participation rates on the labour market. Gender specific demographics are only partially responsible for the gender difference in the GA's.

We also decomposed the generational accounts into specific revenue and expenditure categories to gain further insight into the sources of this gender difference. ${ }^{16}$ The results confirm the above result that the gender difference is mainly driven by the age-profiles. A female newborn expects to pay $45 \%$ less social security contributions than a male newborn (€154,850 instead of $€ 280,006)$. On the expenditure side the average lifetime health-care expenditure is higher for women than for men. ${ }^{17}$

Moving down the other rows in Table 2, the 'rest of life' generational account increases and becomes positive at the age of 8 for men and 17 for women. It reaches a maximum of $€ 211,706$ for men and $€ 37,912$ for women at the age of 23 . From that

\footnotetext{
16 Tables with the decomposition are available from the authors upon request.

17 Average health-care costs are higher for women around the age of 25, which is explained by pregnancy related expenses. But also higher life expectancy of women translates into more health-care costs than for men.
} 
age on, expected educational expenditures and family allowances decline and the present value of future income taxes and social security contributions dominate future old age benefits. From the age of 23 onwards, the GA decreases as the number of years the individual is expected to work shrinks and pension benefits approach in time. The GA already turns negative at the age of 29 for women and at 38 for men. It reaches a minimum at the age of 61 and then starts to increase again since life expectancy declines.

Note that the forward looking assumption of generational accounting makes the figures from Table 2 not comparable across different age groups (hence, across the rows of one column). Since the accounts only measure the average amount of net taxes a representative individual of a given age group has to pay for its remaining lifetime, they only reveal intra-generational differences in the net tax burden of different subgroups, e.g. men and women.

Contrary to what is often thought, the negative generational accounts for a newborn in Table 2 does not answer the question whether Belgian public finances are sustainable in the long run. Table 2 merely illustrates the impact of current policy on currently living generations in Belgium. True, the negative account for a newborn might sound an alarm. But if future demographic evolutions and/or economic growth are favourable enough, the negative GA for a newborn in Table 2 might still be compatible with long-term sustainability. In the next subsection we therefore integrate the GA's into sustainability indicators.

\subsection{Sustainability of Belgian public finances}

Table 3 displays the sustainability indicators derived by using the generational accounts of Table 2 in combination with the assumptions on growth and the longterm demographic projections.

The first indicator concerns the intertemporal public liabilities $\left(I P L_{t}\right)$ of Eq. (9). This consists of explicit debt in $2010\left(B_{t}\right)$, plus all liabilities (or assets) incurred by net tax payments of currently living generations $\left(C U_{t}\right)$ and future liabilities (or assets) incurred by the net tax payments of future generations $\left(F U_{t}\right)$, under the crucial assumption that current and future generations face the same fiscal policy. In 2010 , explicit government debt was equal to $€ 341$ billion, or approximately $97 \%$ of GDP. Under current policy total implicit debt converges to $€ 2507$ billion, leading to

Table 3 Summary of the fiscal stance of Belgium under policy of base year 2010

\begin{tabular}{ll}
\hline Explicit debt (billion $€$ ): $B_{t}$ & 341 \\
Implicit debt (billion $€$ ): $C U_{t}+F U_{t}$ & 2,507 \\
IPL (billion $€$ ): $I P L_{t}$ & 2,848 \\
IPL ( $\%$ of present value of future GDP) & 11.5 \\
IPL ( $\%$ of current GDP) & 808 \\
GA of a representative newborn in $2010(€): G A_{t, t}$ & $-143,786$ \\
GA of future newborn to return to sustainable finances & 181,020 \\
$\quad(€): G A_{t, t+1}^{*}$ & \\
Intergenerational gap $(€): G A_{t, t+1}^{*}-G A_{t, t}$ & 324,806 \\
\hline
\end{tabular}


a total of $€ 2,848$ billion in intertemporal public liabilities. Being different from zero, this clearly reveals a violation of the intertemporal budget constraint, and hence unsustainable Belgian public finances in the long run.

In the literature, these implicit liabilities are expressed in two different ways. The first one, introduced by Raffelhüschen (1999a, b) and in line with the concept of explicit debt, displays IPL against current GDP. In that case total Belgian intertemporal public liabilities are equal to $808 \%$ of current baseline GDP. However, this way of expressing the indicator is often criticized for two reasons. The first is the arbitrariness of the length of the time period used for the flow concept when linking a stock and a flow concept. ${ }^{18}$ Secondly, it does not take into account future growth prospects. It seems more sensible to report intertemporal public liabilities in terms of the present value of the sum of all future GDP's. Applied to our baseline results, we get an IPL which amounts to $11.5 \%$ of projected GDP. ${ }^{19}$

The second way to express long run sustainability consists in looking at the required adjustment in net contributions of future generations to satisfy the intertemporal budget constraint, see Eq. (10). This future GA can be compared to the generational account of a newborn in 2010, since we then compare individuals over their entire life span. Table 3 shows that a future newborn will have to pay net taxes of $€ 181,020$ to restore the intertemporal budget constraint. The intergenerational imbalance consists of the comparison of this future generational account with the one of the newborn of 2010. Given current policy and the need for sustainable public finances in the long run necessitates future generations to pay $€ 324,806$ more taxes than a current newborn. ${ }^{20}$

We stress that this generational imbalance, as informative as it may be, is only a first step, albeit a necessary one, in the more comprehensive discussion about intergenerational equity. In this paper, we do not introduce any normative framework to express value judgements and trade-offs of welfare for, choices by, or resources available to subsequent generations. Therefore, any interpretation of this generational imbalance as 'unjust', is overstretching the framework in which this result has been obtained.

As Haveman (1994) pointed out, these results might be sensitive to assumptions about discount and growth rates. Therefore, Table 8 in the appendix presents a

\footnotetext{
${ }^{18}$ This is analogous to the arbitrariness of considering $100 \%$ of GDP as an alarming level of debt. When choosing quarterly levels of GDP, the same nominal debt level is expressed as $400 \%$, and when choosing a two-year period, the debt level will be $50 \%$. The only value of linking a stock variable to the flow variable GDP, is that it enhances cross country and temporal comparisons with varying GDP's.

19 Another, slightly different, indicator consists in the calculation of the immediate and permanent increase in the primary balance in order to return to sustainability. Our results (not displayed in Table 2) show that to return to long term sustainability, the primary balance should be improved permanently with 11.5 percentage points. A similar indicator is frequently used by the European Commission, under the concept of S2-indicator which equals 5.3 for 2009 (European Commission 2009). However, as stated in Benz and Fetzer (2006), the OECD-method that is used by the European Commission differs from the generational accounting framework. This discrepancy might serve as a partial explanation why the S2indicator differs from the result in our work.

20 Our results are in line with the ones obtained by Hagist et al. (2009a) who analyse the fiscal stance of Austria in 2005. The generational account of a newborn equals $€-130,000$, and the future generational account needed to restore sustainability equals $€ 239,900$, leading to an intergenerational gap of $€ 369,900$.
} 
Table 4 Share revenues and expenditures GDP 2010 and present value all GDP

\begin{tabular}{lrrrc}
\hline & $\begin{array}{l}\text { \% GDP } \\
\text { 2010 }\end{array}$ & $\begin{array}{l}\text { \% Present } \\
\text { value all GDP }\end{array}$ & $\begin{array}{l}\text { Difference } \\
\text { (pct. points) }\end{array}$ & $\begin{array}{c}\text { Share in total change } \\
\text { revenue or expenditure }\end{array}$ \\
\hline Capital taxation & 0.7 & 1.0 & +0.3 & 3.8 \\
Income taxation & 12.2 & 14.0 & +1.8 & 23.9 \\
Corporate taxation & 2.8 & 3.1 & +0.4 & 5.3 \\
Indirect taxation & 12.3 & 14.8 & +2.4 & 32.2 \\
Social security contributions & 13.6 & 15.0 & +1.4 & 19.0 \\
Non-fiscal non-parafiscal revenues & 5.2 & 5.4 & +1.2 & 15.9 \\
Total revenues & $\mathbf{4 6 . 8}$ & $\mathbf{5 3 . 3}$ & $+\mathbf{7 . 4}$ & $\mathbf{1 0 0}$ \\
Wages public sector & 9.3 & 11.4 & +2.1 & 11.6 \\
Birth allowances & 0.0 & 0.0 & +0.0 & 0.1 \\
Family allowances & 1.6 & 1.8 & +0.1 & 0.7 \\
Education & 4.5 & 5.2 & +0.7 & 3.9 \\
Health-care & 7.0 & 13.7 & +6.8 & 37.7 \\
Sickness and disability benefits & 1.2 & 1.4 & +0.2 & 1.1 \\
Unemployment benefits & 1.6 & 1.1 & -0.4 & 2.4 \\
Pension benefits & 8.3 & 13.8 & +5.5 & 30.8 \\
Other & 13.3 & 16.3 & +3.0 & 16.7 \\
Total Expenditures & $\mathbf{4 6 . 8}$ & $\mathbf{6 4 . 8}$ & $+\mathbf{1 7 . 9}$ & $\mathbf{1 0 0 . 0}$ \\
\hline
\end{tabular}

sensitivity analysis in which we vary the growth rate from 1.25 to $1.75 \%$, and the discount rate from 2 to $5 \%$. The intertemporal public liabilities in terms of the present value of the sum al all future GDP's fluctuates between 9.9 and $14.4 \%$. The assessment of unsustainable Belgian public finances does clearly not hinge upon the specific growth rate and discount rate used in Table 3.

For policymakers, it may be interesting to see the composition of these implicit liabilities. Table 4 decomposes the implicit liabilities by the different revenue and expenditure categories. The difference between total revenues $(53.3 \%)$ and expenditures $(64.8 \%)$ in percentage of the present value of the sum of all future GDP equals the IPL-indicator from Table 3, $11.5 \%$. In comparison with their share of GDP of base year 2010, total revenues increase with 7.4 percentage points whereas total expenditures increase with 17.9 percentage points. In the rightmost column of Table 4 we show the share of each component in the total percentage point change of revenues and expenditures. The increase in revenues can be mainly assigned to changes in indirect taxation $(32.2 \%)$ and income taxes $(23.9 \%)$. Increasing health care costs $(37.7 \%)$ are a more important factor than pensions $(30.8 \%)$.

\subsection{Main determinants of the unsustainable public finances}

In this section, we investigate the main determinants of the unsustainability of the previous section, by simulating counterfactuals. Table 5 summarizes the results of four simulations. 
Table 5 Fiscal sustainability (IPL as \% of future GDP) for simulated counterfactuals

\begin{tabular}{lcc}
\hline & $\begin{array}{l}\text { IPL in \% of } \\
\text { future GDP }\end{array}$ & $\begin{array}{l}\text { Relative } \\
\text { importance (\%) }\end{array}$ \\
\hline Baseline & 11.5 & 100.0 \\
No explicit debt & 10.1 & 12.1 \\
No ageing & 2.7 & 76.5 \\
No increased health-care costs & 9.3 & 19.1 \\
Employment rate age group 50-65 from 41 to 50\% & 10.3 & 10.4 \\
Employment rate age group 50-65 from 41 to 70\% & 6.1 & 47.0 \\
\hline
\end{tabular}

Since Belgian public finances have been characterized by one of the largest explicit debts in the European Union for several decades, it is often put forward that the current fiscal imbalance is due to this 'burden of the past'. Indeed, in 2010, the Belgian government faced an explicit debt of $97 \%$ of GDP. The first simulation analyses how sustainability is affected in the counterfactual where there would be no explicit debt. Table 5 shows that, expressed relative to future GDP, intertemporal public liabilities would decline from $11.5 \%$ in the baseline to $10.1 \%$. Hence, only $12.1 \%$ of the sustainability gap can be attributed to the current debt level.

In the second counterfactual, we isolate the effect of ageing by removing the demographic change from the calculations of the GA's. We hold the age structure of the 2010 population constant. Table 5 shows that the sustainability problem expressed in percentage of the present value of future GDP is now substantially reduced from 11.5 to $2.7 \%$. This means that 8.8 percentage points out of the long run imbalance of $11.5 \%$ (or $76.5 \%$ ) can be assigned to demographic changes.

In the third simulation we remove the more than proportional increase in per capita health expenditures. This shows that only $19.1 \%$ of the sustainability gap can be attributed to this factor.

Finally, we used the comparative advantage of our microsimulation tools to simulate the effect of an increase in employment on the generational accounts. In line with one of the goals of the Lisbon Strategy, we analyzed the improvement of public finances when the employment of elderly workers increases. We simulate the effect on government revenues and expenditures due to this increase in employment, by means of the microsimulation model MEFISTO running on the micro data of the Belgian database of the European Union Statistics on Income and Living Conditions (EU-SILC). ${ }^{21,22}$

\footnotetext{
${ }^{21}$ MEFISTO is a tax benefit calculator which calculates for each household the net disposable income, corresponding to gross income components under given tax and benefit rules. It is an expanded version of the Belgian module of EUROMOD, as developed in the SBO-project "FLEMOSI: A tool for ex ante evaluation of socio-economic policies in Flanders", funded by IWT Flanders. For more details on the FLEMOSI-project, see www.flemosi.be. For more information on the original EUROMOD-model, see Sutherland (2001) and https://www.iser.essex.ac.uk/euromod/.

22 EU-SILC is based on a two-step sampling procedure and representative for the Belgian population in private households (persons living in collective households and in institutions are excluded from the target population). The data used here were collected in the second half of 2006 and contain information on income received in 2005 . The sample consists of 5,860 households or 14,329 individuals.
} 
According to the EU-SILC data, the employment rate of elderly workers (50-65 year) was approximately $41 \%$ in 2005. This is low compared to other EUcountries. For example, the employment rate of elderly in 2005 equals $44 \%$ in Austria, $51 \%$ in France, $54 \%$ in the Netherlands and $62 \%$ in the United Kingdom (see Zaida 2007). We therefore considered it sensible to investigate the effect on sustainability of increasing the employment rate at least up to $50 \%$ for this age group. We also pushed the employment rate to the much higher level of $70 \%$.

To carry out the simulation, we randomly draw people from the labour force between 50 and 65 years old who are either inactive, unemployed or pensioned. Assuming they work full time, we calculated their gross income, and reduced their unemployment or pension payments to zero. ${ }^{23}$ MEFISTO produces their corresponding disposable income, and hence also the taxes and social security contributions they pay. The microsimulation exercise reveals that the increase in the employment rate of elderly to 50 and $70 \%$ leads to an increase in personal income tax revenue of respectively 3.0 and $11.1 \%$, an increase in social security contributions of 5.3 and $18.6 \%$, a decrease in pension payments of 3.4 and $15.1 \%$, and a decrease in unemployment benefits of 4.5 and $12.2 \%$.

We then translate this increased employment rate of the age group 50-65 into the age-profiles of taxes and expenditures and recalculate the GA's and the sustainability indicators. The last two rows of Table 5 show that the necessary adjustment in terms of GDP decreases from 11.5 to $10.3 \%$ when the activity rate goes up to $50 \%$, and nearly halves to $6.1 \%$ with an employment rate of $70 \%$. Mainly the latter is a substantial reduction of the sustainability gap. But even in that very optimistic scenario, more policy changes are needed to tackle long term fiscal unsustainability.

\section{Regional generational accounts}

In this section we derive the gender specific generational accounts for the three Belgian regions, i.e. Flanders, Wallonia and Brussels to investigate the long run budgetary impact of the region specific demographic evolution shown in Fig. 1. We therefore assigned as much as possible revenues and expenditures from Table 1 to residents by regions, construct region-specific age profiles, and used region specific population projections. Note that this does not amount to the construction of regional budgets with a complete picture of regional revenues and expenditures, as determined by regional tax and expenditures competences, and by the Belgian Special Finance Act which determines grants to regions and communities. Instead, we directly decompose revenues and expenditures on the basis of the residence of

\footnotetext{
23 In order to assign these people gross wages, an hourly gross wage is essential. However, the EU-SILC does not report an hourly wage for people who are not working at the time of the survey. We therefore estimated and imputed an hourly wage by means of a Heckman selection model (see Decoster and Vanleenhove 2012).
} 
Table 6 Generational accounts by region (in Euro)

\begin{tabular}{lrrr}
\hline Age & \multicolumn{1}{c}{ Flanders } & Wallonia & \multicolumn{1}{c}{ Brussels } \\
\hline 0 & $-112,918$ & $-288,750$ & $-124,140$ \\
15 & 84,023 & $-106,296$ & 56,837 \\
30 & 79,961 & $-73,427$ & 60,739 \\
45 & $-177,040$ & $-234,017$ & $-112,755$ \\
60 & $-355,945$ & $-354,126$ & $-312,049$ \\
75 & $-257,070$ & $-268,192$ & $-273,464$ \\
90 & $-139,240$ & $-140,018$ & $-145,597$ \\
\hline
\end{tabular}

the individual or household. Therefore we will only report regionalized GA's in this section, and not sustainability indicators, comparable to the Belgian ones in Table 3.

To allocate the Belgian aggregate expenditures and revenues from Table 1 to the three regions, we mainly used the microsimulation model MIMOSIS, since the micro-data of this model to contain a region identifier at the individual level. For capital taxes, corporate taxes, indirect taxation and "other contributions", no regionalized information was available, and we distributed them in proportion to regional population size. Second, if available from micro data, we calculated regionalized gender specific age profiles for each revenue and expenditure component. If not, we use the gender specific age profiles from the Belgium case. ${ }^{24}$ Finally, we inserted region specific population projection of the Federal Planning Bureau and the National Institute of Statistics from 2007 to 2060 and extended these to 2310 in a similar way as for the Belgium population. Since there is no gender-specific projection at the regional level, we transplanted the gender projection of the total Belgian population into the regional population projections. ${ }^{25}$ Analogous to the calculations for Belgium in the previous section, we assume an annual growth rate of productivity of $1.5 \%$, except for health-care expenditures, and a discount rate of $3 \%$.

Table 6 shows generational accounts for Flanders, Wallonia and Brussels. It reveals how different the generational accounts are for the regions. Under current policy, and-more importantly_-given the current age profiles of different taxes and expenditures, reflecting the current socio-economic situation in the regions, a representative newborn in Wallonia is expected to receive on average almost $€ 175,000$ more than a Flemish newborn over their expected lifetime. Between Flanders and Brussels the difference at the level of newborns is much smaller. The age pattern of the GA's is similar for all three regions and comparable to what we found in the Belgian generational accounts.

Since regional differences in GA's might be caused by both differences in age profiles and different demographic evolutions, we have, in line with the discussion at the Belgian level in Table 2, simulated the GA of Wallonia and Brussels under

\footnotetext{
${ }^{24}$ We could produce region specific age profiles for personal income taxes, social security contributions, sickness-disability benefits, unemployment benefits and pensions.

25 The regional decomposition of expenditures and revenues, as well as the regionalized age profiles can be obtained from the authors upon request.
} 
Table 7 Counterfactual simulations of regional generational accounts

\begin{tabular}{lrrr}
\hline & Flanders & Wallonia & \multicolumn{1}{c}{ Brussels } \\
\hline Baseline 2010 & $-112,918$ & $-288,750$ & $-124,140$ \\
All regions have Flanders age-profile for net taxes & $-112,918$ & $-130,388$ & $-29,447$ \\
No ageing & 27,812 & $-153,762$ & $-47,874$ \\
No ageing, all regions have Flanders age-profile & 27,812 & 16,068 & 59,146 \\
\hline
\end{tabular}

the assumption of a similar age profile as in Flanders. The result is displayed in the second row of Table 7.

Removing differences in age profiles of net taxes and only keeping differences in demographic projections leads to a drastic change in the regional GA's. The counterfactual GA for a representative Walloon individual is now almost the same as the one for a Flemish newborn. The difference between both accounts reduces from $€ 175,832$ in the baseline to only $€ 17,470$. This clearly illustrates that the large difference in the baseline GA for Flanders and Wallonia is almost entirely due to the current socio-economic situation in Wallonia, as reflected in the age-profiles. The improvement in the Brussels GA when using the Flanders age profile for taxes and expenditures is even more spectacular and can be explained by divergent regional migration patterns. As shown in a study commissioned by the Flemish government (Sum Research 2006), the migration pattern for Brussels is different than the other two regions. The Brussels region is confronted with a positive net migration of people of working age and a negative net migration of elderly. As such, relatively few benefits such as pension or health care must be paid in Brussels in comparison with the amount of taxes collected from the active working population. This migration pattern is not observed in the other two regions and explains why we see this improvement in the counterfactual GA for Brussels when removing all socioeconomic factors.

The predominance of socio-economic factors in the explanation of regional differences in the GA's is confirmed by simulation of a counterfactual in which we remove ageing from the demographic projections (row 3 in Table 7) After all, Table 4 revealed that ageing is the main determinant of unsustainable Belgian public finances and Fig. 1 showed a clear regional pattern in the change of the dependency ratio. Removing ageing from the demographic projection leads to an improvement in the GA for Flanders of $€ 85,106$ (the difference between -112,918 in the first row and 27,812 in the third row of Table 7). For Brussels the GA improves by $€ 76,266$, whereas the change in GA for Wallonia is equal to $€ 134,988$ (the difference between $-288,750$ and $-153,762$ ). This larger effect for Wallonia can be explained by the fact that ageing is more challenging in Wallonia, as can be seen in Fig. 1. The regional difference in GA remains however large in comparison to the simulation in which each regions faces the same Flemish socio-economic situation. Therefore, far more important than regional differences in demographic projections is the regional difference in socio-economic situation. This also shows 
up in the GA of a Flemish newborn turning positive when neutralizing the effect of ageing.

Hence, given the previous two simulations, it does not come as a surprise that all three regional GA's turn positive when we simultaneously remove the ageing component and endow Wallonia and Brussels with the Flemish age profiles of net taxes. The results are in the bottom row of Table 7 . Compared to the difference in the generational account of a newborn in the second row of Table 7, i.e. $€ 17,470$ between Flanders and Wallonia, the difference between the two regions decreases further $(€ 11,744)$. This does indeed illustrate that the demographic evolution and more specifically the ageing of the population, is more challenging in Wallonia than in Flanders. But this effect is relatively small compared to the effect of socioeconomic factors, reflected in the age-profiles of net taxes. This holds a fortiori for the Brussels region.

\section{Conclusion}

Since the financial crisis turned into a sovereign debt crisis, fiscal imbalances are in the centre of the public debate. With fiscal deficit and debt level forecasts of respectively -3.1 and $100.5 \%$ for 2012 Belgium is not an exception to this general picture. There is no doubt that these figures deserve attention. But an exclusive and frenetic focus on these cyclical and short term problems threatens to conceal the long term picture of structural and long term fiscal imbalances. It is well known that the current deficit and explicit debt ratio only measure annual flows of expenditures and receipts. They ignore future liabilities such as future pension entitlements and health care costs which, due to an ageing population, are going to increase substantially in the near future. As an alternative or complementary way of looking at the fiscal stance of countries, Auerbach et al. (1991) introduced the method of generational accounting.

This paper derived generational accounts for Belgium using data of 2010, and can be considered an update for Belgium of earlier work by Dellis and Lüth (1999) and Stijns (1999). We also introduced some new elements and improvements. First, we made use of microdata and microsimulation models to derive gender specific age profiles of the most important taxes and benefits. Secondly, we determined the relative contribution of the most important factors of long run unsustainability by simulation of counterfactuals, such as the removal of initial debt, ageing or increased employment rates. For the latter we again made use of microsimulation techniques. Finally we disentangled Belgian generational accounts into regional accounts for Flanders, Wallonia and Brussels.

In line with other studies which investigate the long run sustainability of Belgian public finances (e.g. Saintrain 2010), we conclude that current fiscal policy, when confronted with the demographic change ahead, violates the intertemporal government budget constraint. According to our calculations Belgium faces a long term structural deficit of $11.5 \%$ of future GDP. Contrary to what is often put 
forward in public debates, the current level of explicit debt only plays a minor role in explaining this sustainability problem. Ageing and the related increase in age related expenditures are the main drivers of the long run fiscal imbalance and the high level of implicit debt. Only $12.1 \%$ of the sustainability gap can be attributed to explicit debt, whereas $76.5 \%$ of the challenge is due to ageing.

The regionalized generational accounts revealed that lower participation rates and higher unemployment in Wallonia translate into an average Walloon newborn to receive almost three times as much from the government than an average newborn in Flanders. In Brussels, a more favourable demographic outlook compensates an equally adverse socio-economic situation. Our simulations showed that regional differences are to found primarily in the age-profiles, reflecting wide differences in the regional socio-economic situations.

As pointed out by Haveman (1994), the method of generational accounting has some major drawbacks. The results are obtained in a purely arithmetic framework, which means that, unlike in a genuine economic model, no economic interactions are taken into account. The methodology only summarizes the combination of current budgetary and social policy with future demographic evolution in an accounting framework. Therefore, the results presented in this paper should not be read as a 'prediction'. Indeed, we do know with certainty that both current policy and the economic environment will change in the years, let alone decades, ahead.

We are even more firm in our warning not to interpret these results as pointing towards intergenerational injustice. For that purpose one needs an elaborated normative framework to trade-off welfare between different generations. Economic growth, further increases in longevity and uncertainty are but some elements which make this framework far from obvious and certainly beyond the scope of this paper. However, these caveats do not make our calculations of generational accounts less valuable. They can serve as an indispensable input to these other models, and feed an informed normative debate. Moreover, we hope that these the results help to advocate a shift of attention of policymakers from the current short term deficit to the real long term structural challenges.

Acknowledgments For useful comments on earlier versions of this paper, we are grateful to Christian Hagist, Stefan Moog, Lionel Artige, Sergio Perelman, Pierre Pestieau, Erik Schokkaert, Guy Van Camp (for the MIMOSIS data), Dirk Verwerft and participants of the EUROMOD workshop at the Baltic International Centre for Economic Policy Studies (BICEPS) in Riga, Latvia October 12-14 2011. We also thank two anonymous referees for their useful remarks. The usual disclaimer applies. Besides financial support from IWT Flanders in the SBO-project "FLEMOSI: A tool for ex ante evaluation of socioeconomic policies in Flanders", we also benefited from funding by Federal Public Service for Science Policy (BELSPO) under contract no. TA/00/39 (BELDEBT).

\section{Appendix}

See Fig. 2; Table 8 

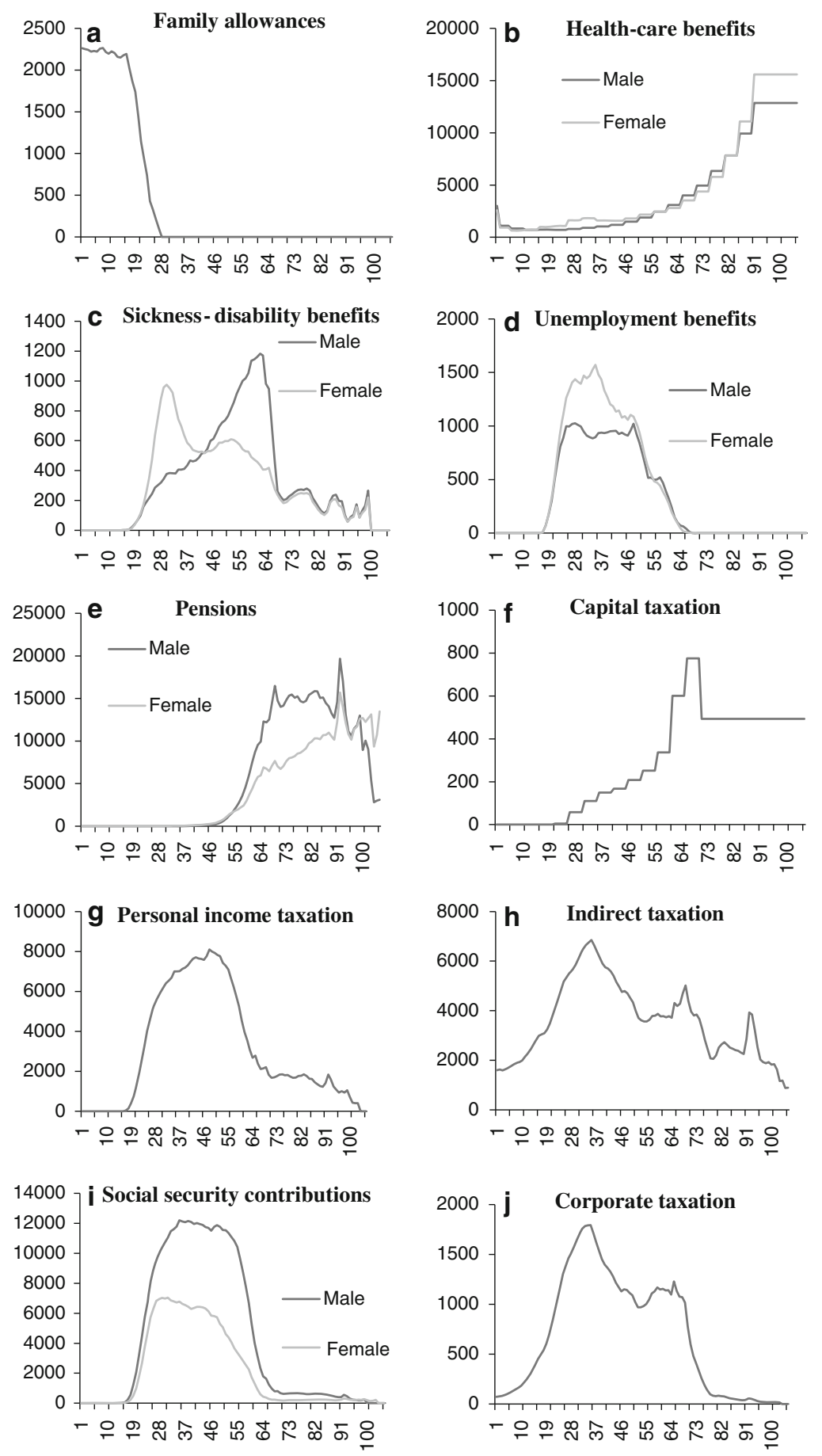

Fig. 2 Age profiles for Belgium: average benefit, tax or contribution in $€$ per year by age group 
Table 8 Sensitivity results for the Belgian generational accounts in baseline of 2010

\begin{tabular}{lllll}
\hline $\begin{array}{l}\text { Productivity } \\
\text { growth }(\%)\end{array}$ & $\begin{array}{l}\text { Discount } \\
\text { factor }(\%)\end{array}$ & $\begin{array}{l}\text { Male } \\
\text { GA }(€)\end{array}$ & $\begin{array}{l}\text { Female } \\
\text { GA }(€)\end{array}$ & $\begin{array}{l}\text { IPL as \% of } \\
\text { present value } \\
\text { of future GDP }\end{array}$ \\
\hline 1.25 & 2 & $-146,348$ & $-338,996$ & 13.5 \\
& 3 & $-73,207$ & $-192,867$ & 11.5 \\
& 4 & $-60,114$ & $-139,060$ & 10.7 \\
$\mathbf{1 . 5 0}$ & 5 & $-66,493$ & $-120,723$ & 10.4 \\
& 2 & $-175,665$ & $-392,958$ & 13.9 \\
& $\mathbf{3}$ & $-\mathbf{7 9 , 0 9 7}$ & $-\mathbf{2 1 1 , 6 6 5}$ & $\mathbf{1 1 . 5}$ \\
& 4 & $-58,020$ & $-144,385$ & 10.5 \\
1.75 & 5 & $-62,482$ & $-121,322$ & 10.1 \\
& 2 & $-214,037$ & $-460,566$ & 14.4 \\
& 3 & $-88,218$ & $-235,789$ & 11.5 \\
& 4 & $-56,824$ & $-151,642$ & 10.3 \\
& 5 & $-58,494$ & $-122,505$ & 9.9 \\
\hline
\end{tabular}

The baseline used in the text is put in bold (growth rate of $1.50 \%$ and discount rate of $3 \%$ )

\section{References}

Ameco (2012) Annual macro-economic data of the directorate general of economic and financial affairs of the European commission, downloaded on August 6th 2012 from http://ec.europa.eu/economy_ finance/ameco/user/serie/SelectSerie.cfm

Auerbach AJ (2011) Long-term fiscal sustainability in major economies, BIS working papers No 361

Auerbach AJ, Gokhale J, Kotlikoff L (1991) Generational accounting: a meaningful alternative to deficit accounting. Tax Policy Econ 5:55-110

Auerbach AJ, Gokhale J, Kotlikoff L (1994) Generational accounting: a meaningful way to evaluate fiscal policy. J Econ Perspect 8(1):73-94

Auerbach AJ, Kotlikoff L, Leibfritz W (1999) Generational accounting around the world, NBER Books. National Bureau of Economic Research, Inc

Benz U, Fetzer S (2006) Indicators for measuring fiscal sustainability: a comparison of the OECD method and generational accounting. Finanz Arch 62:125-129

Bonin H (2000) Generational accounting: theory and application. Springer, Heidelberg

Cattoir P, Docquier F (2004) Debt sharing and secession: a generational accounting approach. Reg Stud 38(3):293-303

Decoster A, De Swerdt K, Maréchal C, Orsini K, Perelman S, Rombaut K, Van Camp G, Verbist G (2007) MIMOSIS: a Belgian microsimulation model for social security and personal income taxes, Report for Belgian FPS Social Security

Decoster A, De Swerdt K Loughrey J, O’Donoghue C, Verwerft D (2009) Comparative analysis of the distributional impact of combined changes in direct and indirect taxes and benefits for five European countries, Workpackage 3.6 of accurate income measurement for the assessment of public policies (AIM-AP,EU-Contract no 028412), Leuven

Decoster A, Loughrey J, O'Donoghue C, Verwerft D (2010) How regressive are indirect taxes? A microsimulation analysis for five European countries. J Policy Anal Manag 29(2):326-350

Decoster A, Flawinne X, Vanleenhove P (2011) Generational accounting in Belgium: fiscal sustainability at a glance, FLEMOSI discussion paper 9, Leuven, available at: http://www.flemosi.be/

Decoster A, Vanleenhove P (2012) In-work taxcredits in Belgium: an analysis of the Jobkorting using a discrete labor supply model, Brussels Economic Review 55(2):121-151

Dellis A, Lüth E (1999) Belgium can fiscal policy cope with debt and ageing? In: European Commission (eds.), Generational accounting in Europe European economy, Brussels, 29-40 
European Commission (2009) Sustainability report 2009. European economy, 9

European Commission (2010) Public finances in EMU-2010. European economy, 4

Hagist C (2008) Demography and social health insurance: an international comparison using generational accounting. Beiträge zum Gesundheitsmanagement, Nomos

Hagist C, Klusen N, Plate A, Raffelhüschen B (2005) Social Health Insurance- The major driver of unsustainable fiscal policy? Forschungs Zentrum Generationen Verträge, Discussion Paper no.1

Hagist C, Deeg V, Moog S (2009a) The fiscal outlook in Austria: an evaluation with generational accounts. Empirica 36:475-499

Hagist C, Moog S, Raffelhüschen B, Vatter J. (2009) Public debt and demography—an international comparison using generational accounts, Cesifo research reports 4/2009

Haveman R (1994) Should generational accounts replace public budgets and deficits? J Econ Perspect $8(1): 95-111$

Liégeois P (2001) The ageing of the population and justice between generations: a computable general equilibrium and generational accounting approach for Belgium. In: Fossati A, Wiegard W (eds) Policy evaluation with computable general equilibrium. Routledge, London, pp 203-215

Newhouse JP (1992) Medical care costs: how much welfare loss? J Econ Perspect 6(3):3-21

Raffelhüschen B (1999a) Generational accounting: method data and limitations. Eur Econ Rep Stud 6:17-28

Raffelhüschen B (1999b) Generational accounting in Europe. Am Econ Rev 89(2):167-170

Raffelhüschen B, Moog S (2011) Ehrbare Staaten? Tatsächliche Staatsverschuldung in Europa im Vergleich, Stiftung Marktwirtschaft, Nr, pp.115

Saintrain M (2010) Herziening van het Belgisch budgettair federalisme: vragen omtrent de budgettaire houdbaarheid en omtrent budgettair beleid en economische cyclus, Federaal Planbureau, Working Paper 23-10

Stijns JP (1999) Generational accounts for Belgium. In: Auerbach AJ, Kotlikoff L, Leibfritz W (eds) Generational accounting around the world. University of Chicago Press, Chicago, pp 161-176

Sum Research (2006) Ruimtelijke analyse van de migratie in en naar Vlaanderen, De Vlaamse Overheid, Departement RWO

Sutherland H (2001) EUROMOD: an integrated European benefit-tax model, Euromod Working Paper No. EM9/01

Sutherland H, Decoster A, Matsaganis M, Tsakloglou P (2009) Accurate income measurement for the assessment of public policies: final report, EUROMOD Working Papers EM7/09

Zaida A (2007) Employment of older workers in EU25, TILDA/ASPEN conference active ageing and labour market trajectories, presentation 